\title{
Power Quality Impact of High Capacity End-Users
}

\author{
N. Golovanov1ㅜ, G. C. Lazaroiu², Student Member, IEEE, M. Roscia ${ }^{3}$ \\ and D. Zaninelli, Senior Member, IEEE \\ ${ }^{1}$ Department of Electrical Engineering, University Politehnica of Bucharest, Splaiul \\ Independentei 313, Bucharest, \\ ${ }^{2}$ Department of Electrical Engineering, University Politehnica of Bucharest, Splaiul \\ Independentei 313, Bucharest, \\ ${ }^{3}$ Department of Progettazione e Tecnologie, Università di Bergamo, \\ ${ }^{4}$ Department of Electrical Engineering, Politecnico di Milano, \\ piazza Leonardo da Vinci 32, Milano 20133, \\ 1,2Romania \\ ${ }^{3,4}$ Italy
}

\section{Introduction}

The random load variation, as in case of the arc furnaces, determines random voltage variations at the supply bus-bars., the can affect the power quality delivered to other customers, supplied by the same bus-bars [1-3]. The voltage flicker level, sensed by the human eye as variations of the light sources flux is determined using the flickermeter, which considers the irritability sensation of the human eye when a threshold level of the supply voltage is exceeded.

To quantify the amplitude of such disturbance, reference is made to the instantaneous flicker sensation $S(t)$. The value of $S(t)$ is measured by means of an instrument, the so-called flickermeter. The setting-up of the flickermeter model is done in Simulink, the simulation tool, in the MATLAB environment. The main advantage of this software product is that it makes it possible to support an object programming procedure, with a circuit representation obtained by means of graphic blocks associated with the different power system components.

The flickermeter model is a conventional analog one, in agreement with the models proposed in current standards that of the necessity to comparative analyses between innovative equipment and conventional architectures, whose disturbances were measured using analog instruments [4].

The present paper deals with the case study of an existing ac arc furnace facility. The $110 \mathrm{kV}$ monitoring campaign was conducted using the ION 7600 equipment. The main power quality indices regarding harmonics and flicker levels are reported in the paper with reference to IEEE standards. 


\section{AC Furnace}

The ac furnace, from the system operator point of view, is a highly polluting load: the real and imaginary power variations necessary for the network causes severe harmonics and voltage flicker such that the system operator must establish limits for the disturbances generated by the load. Independently from the type and amplitude of the admissible disturbances, the critical point in analyzing the electrical perturbation of an ac arc furnace is constituted by the high voltage bus, where the network operator evaluates the conformity with the contractual parameters. These parameters are stipulated by standards [5].

Fig. 1 shows the layout of an ac arc furnace supply system. As it can be seen, the intermediate voltage level is of high importance due to the fact that here the filtering processes occur.

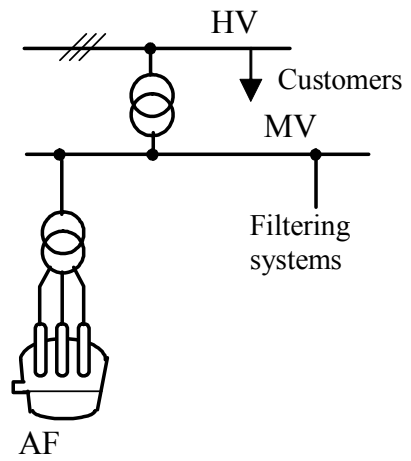

Fig. 1. AC arc furnace connection layout

The power quality evaluation considering the voltage flicker impact is evaluated in accordance with [3]:

- considered data correspond to a week observation period;

- $\quad$ every 10 minutes consecutives values of the short-term voltage index are analyzed;

- the values obtained when the bus voltage is outside the range $\mathrm{V} \pm 15 \%$ or when voltage sags with depth higher or equal to $15 \%$ of the rated voltage are considered not valid;

- the index $P_{l t}$ is computed considering 12 valid and consecutives values of the $P_{s t ;}$;

- $\quad$ the number of valid values, $N$, of $P_{l t}$ measure is determined;

- the number, $N_{1}$, when $P_{l t}$ exceeds unity is determined;

- the condition $N_{1} / N \leq 0,05$ is checked.

\section{UIE Flickermeter}

Since, from the point of view of analyzing the signal, the flicker is a low-frequency modulation of the network voltage at $50 \mathrm{~Hz}$, the purpose of the flickermeter is to separate the carrier from the modulating wave, weight the effects of the latter based on human sensitivity to the disturbance, and return the instantaneous flicker sensation signal.

In the history of electronics, many kinds of architecture have been used to create such instruments. Some of them are based on analog filtering of the voltage at the common point of coupling in order to extract the instantaneous disturbance level and apply it to a predefined weighting curve (shown in Fig. 2) for weighting its incidence and ascertaining its severity. 


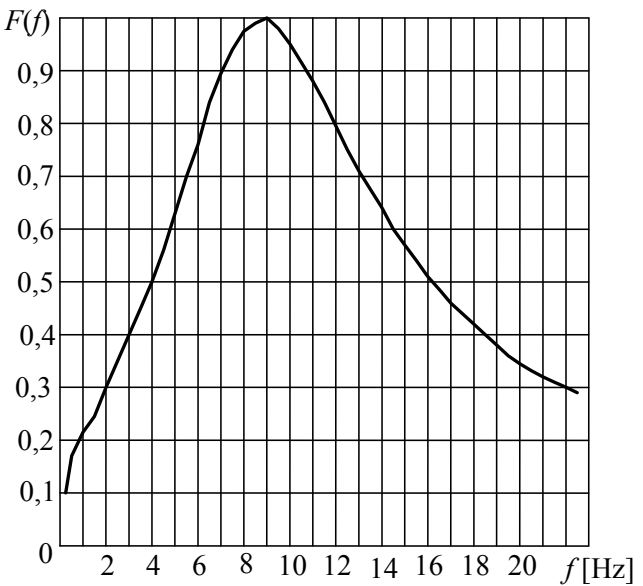

Fig. 2. Weighting curve proposed by UIE (International Union for Electro-thermal Applications)

Fig. 3 shows the layout of the UIE flickermeter, a standardized instrument for measuring the flicker obtained by simulation and by stochastic analysis of the response of the lamp-eyebrain chain to voltage fluctuations.

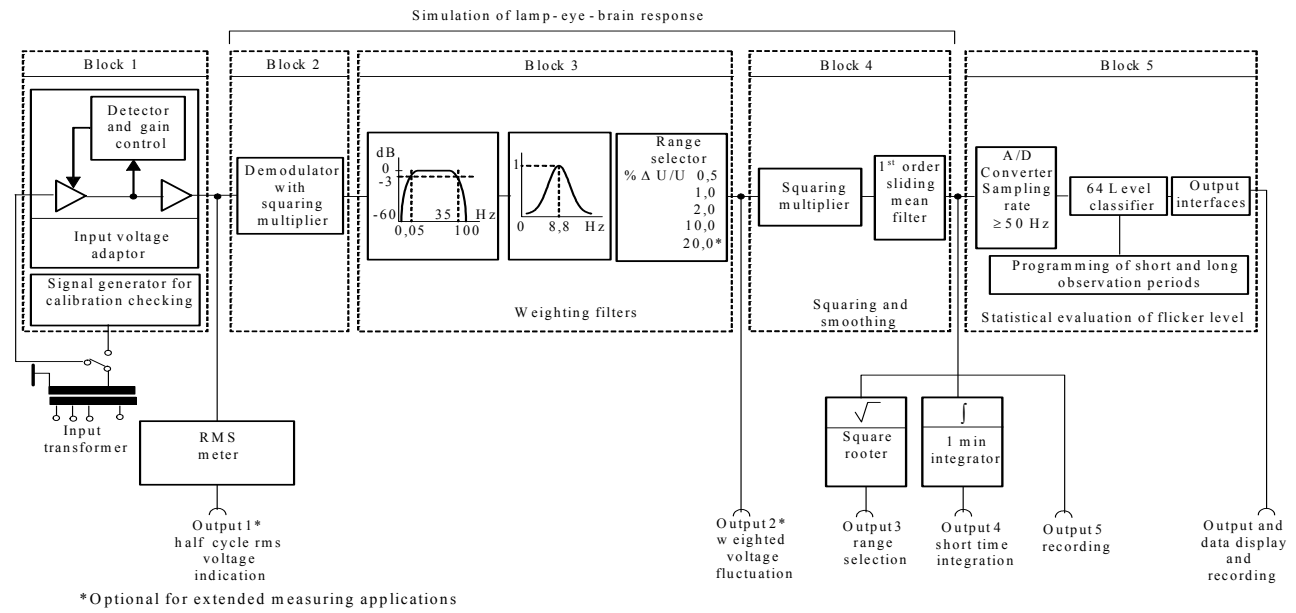

Fig. 3. General layout

The input signal consists of the $50 \mathrm{~Hz}$ network on which flicker is superimposed in the form of amplitude modulation and enters Block 1, the so-called "normalization block", after which a transformer reduces its voltage level to values compatible with the electrical specifications of the electronic components located downstream.

Block 1 contains a signal generator for checking the flickermeter setting in the field and a circuit for normalizing, at the internal reference level, the rms value of the input voltage at network frequency. 
In this way, flicker measurements are made independent of the actual input voltage, whose variations $(\Delta V)$ are expressed as a relative value of the rated voltage $\Delta V / V_{n}$. This function is obtained by acting on the gain of an amplifying stage by means of a suitable control signal obtained for comparison between the effective output voltage value and a reference signal.

The subsequent blocks (from 2 to 4 ) react to the signal by simulating the behavior of the lamp-eye-brain chain.

Block 2 is a quadratic demodulator for separating the modulating fluctuation $(\Delta V)$ from the carrier wave (network frequency). Block 3 consists of two filters in cascade and by a scale selector of the sensitivity that may precede or follow the selection filter circuit. The first filter eliminates from the output voltage of the quadratic demodulator the dc component and that of the dual frequency in respect of network frequency. The second filter, centered at $8.8 \mathrm{~Hz}$, imposes the form of the response in flickermeter frequency on the modulating fluctuation. The "weighting filter" block simulates the response in frequency on the sinusoidal fluctuations in the voltage of the chain consisting of a lamp filled with inert gas with a spiral filament $(60 \mathrm{~W}-230 \mathrm{~V})$, followed by the human eye. The response function is based on the perceptibility threshold ascertained, for each frequency, out of $50 \%$ of the persons taking part in the experiment.

The structure of the flickermeter may be represented through the transfer functions contained in the block diagram in Fig. 4.

This condenses all the signal manipulations required for obtaining in exit the trend of the instantaneous flicker disturbance in accordance with the information supplied by the current standard [4]. In addition, this diagram considers the steps necessary for setting up efficient electronic implementation.

- Block A has the dual function of expressing the instant input voltage as a p.u. value and that of simulating the behavior of the quadratic demodulator;

- Block B has the job of cutting off the dc voltage component, eliminating the signal of the carrier wave and the high-frequency fluctuations found at the exit of the quadratic demodulator;

- Block $\mathrm{C}$ simulates the response in the frequency of the human eye to the voltage fluctuations of an incandescent lamp supplied by a variable sinusoidal voltage;

- Block D squares the signal exiting from Block $C$ by simulating the non-linear perception of the flicker in the eye-brain chain;

- Block $\mathrm{E}$ is a low-pass filter that performs the smoothing action.

In Fig. 5 we find implementation of the functionalities of Block A, in Fig. 6 those of Block B, in Fig. 7 those of the Butterworth filter, in Fig. 8 those of Block C, in Fig. 9 those of Block D, and in Fig. 10 those of Block E.

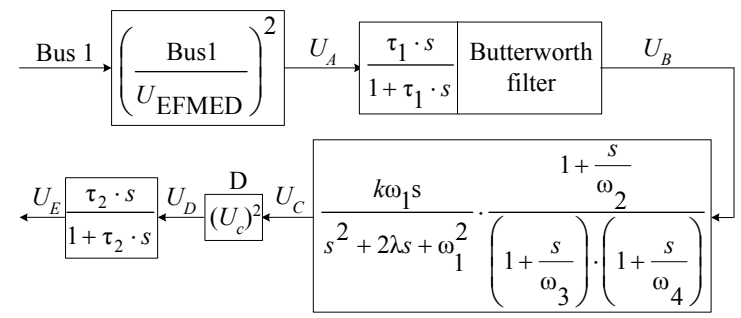

Fig. 4. Block diagram of the flickermeter simulated with Simulink 
Once we have obtained the trend in respect of the instantaneous flicker sensation, we have, from the latter, to calculate the indices that make it possible to evaluate the severity of the disturbance injected into the network [4].

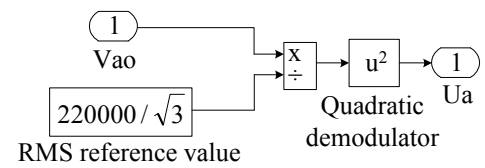

Fig. 5. Diagram of Block A

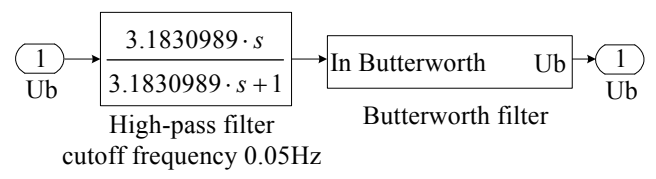

Fig. 6. High-pass filter

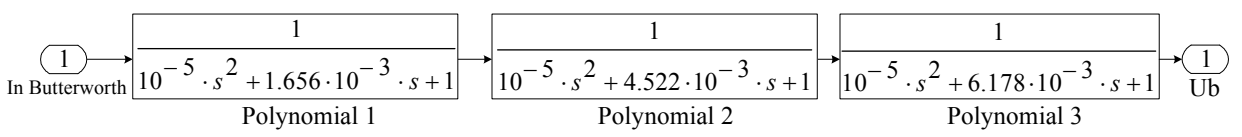

Fig. 7. Butterworth Filter Diagram.

$$
\underset{\frac{\mathrm{Uc}}{1} \rightarrow \frac{100.5499 \cdot s}{s^{2}+51.017077 \cdot s+3308.8017}}{\text { Lamp - Eye - Brain - Chain 1 }} \rightarrow \frac{0.069811 \cdot s+1}{9.43921 \cdot 10^{-4} \cdot s^{2}+0.1371526 \cdot s+1} \rightarrow \frac{1}{\mathrm{Ud}}
$$

Fig. 8. Diagram of Block C

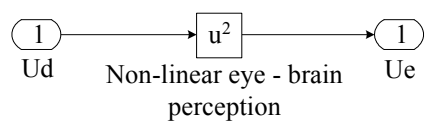

Fig. 9. Diagram of Block D.

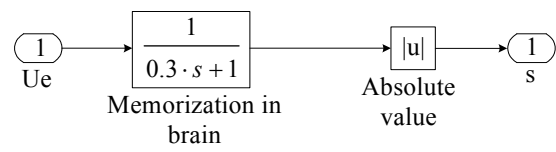

Fig. 10. Diagram of Block E

Fig. 11 shows the voltage waveform at the Block 1 output for a sinusoidal waveform of the rms voltage (Fig. 11(a)) and respectively for a square waveform (Fig. 11(b)). Outputs of the Block 2 for the two considered waveforms are shown in Fig. 11(c) and respectively Fig. 11(d).

The waveforms of the voltages at the output of the Block 3 are shown in Fig. 11(e) and Fig. 11(f). The outputs of the Block 4 are representative for the instantaneous flicker sensation and must be reported to the irritability curve of the human eye. These waveforms are illustrated in Fig. 11(g) and Fig. 11(h), [6]. 


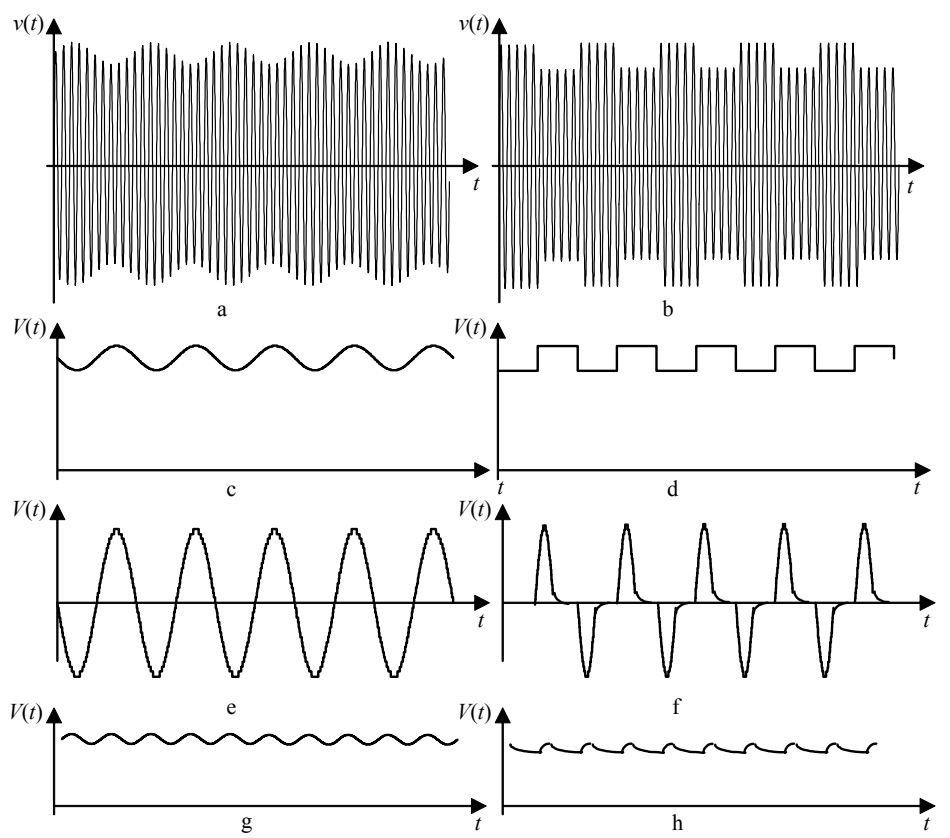

Fig. 11. Waveforms of the voltages in different points of the of the flickermeter scheme, for sinusoidal and square inputs

\section{Case of application}

The case studied is referred to a real plant sited close to Bucharest, in Romania. The measurements were done using the device ION 7600 at the $110 \mathrm{kV}$ voltage level. At PCC the line-to-line voltage is $110 \mathrm{kV}$, the ac arc furnace has 60MVA (see Fig. 12).

The layout of flickermeter connection at the end-user monitored terminals is shown in Fig. 13. The RMS variations of the voltages at PCC are shown in Fig. 14. As it can be seen, during the operation of the ac arc furnace, variations of the voltages at PCC occur.

Fig. 15 shows the real power adsorbed by the ac arc furnace for one week operating period. The initial and the final part of the waveform correspond to a not-operating period of the arc furnace, respectively Sunday. During its operation period, a variable real power necessary for the arc furnace functioning is adsorbed. The imaginary power variation is highlighted in Fig. 16.

In Fig. 17 the RMS variation of the short-term flicker severity $P_{s t}$ values on phase $A$, for the same one week monitoring period, is illustrated. The $95 \%$ value of $P_{s t}$ is 5.28 , exceeding the 0.8 IEEE threshold established for the high voltage networks [7]. This value $P_{s t}=5.28$ can be explained by the fact that the fault level at PCC is 1150MVA.

When voltage flicker sources with long and variable operating cycle (like the arc furnaces) are investigated, the evaluation of the long-term severity flicker is necessary. Fig. 18 illustrates the variation of the long-term flicker severity $P_{l t}$ using the values $P_{s t}$ monitored on 120 minutes period, measured every consecutive 10 minutes. The $95 \%$ value of $P_{l t}$ is 6.95 , greater than the IEEE threshold of 0.6 settled for $P_{l t}$. 
Figs. 19-20 show the phase $A$ waveforms of the power quality indices $T H D_{V}$ and $T H D_{I}$.

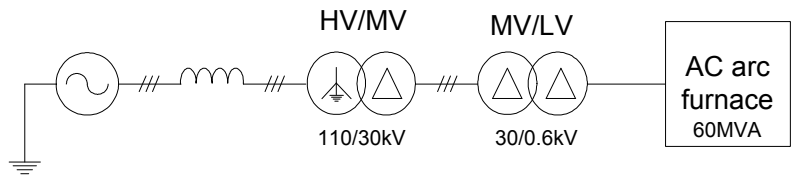

Fig. 12. Simplified diagram of the ac arc furnace power supply.

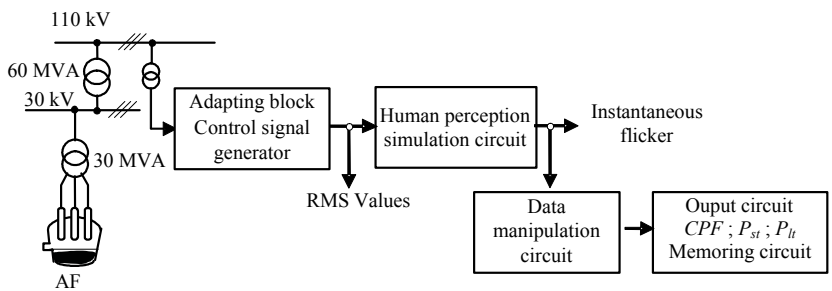

Fig. 13. Layout of flickermeter connection at end-user terminals

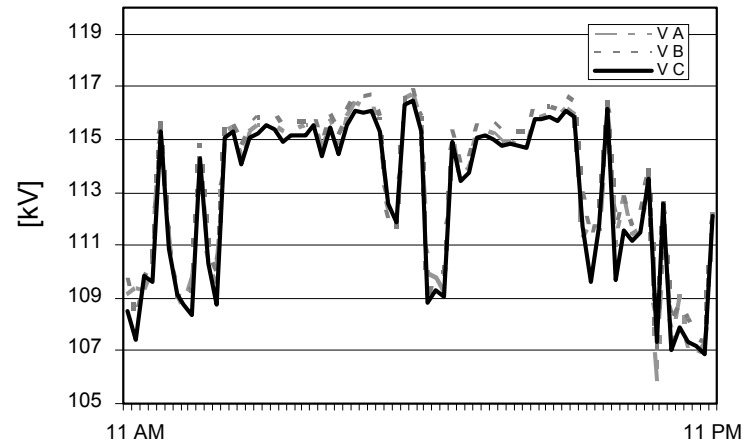

Fig. 14. RMS variation of the ac voltages at PCC (HV level).

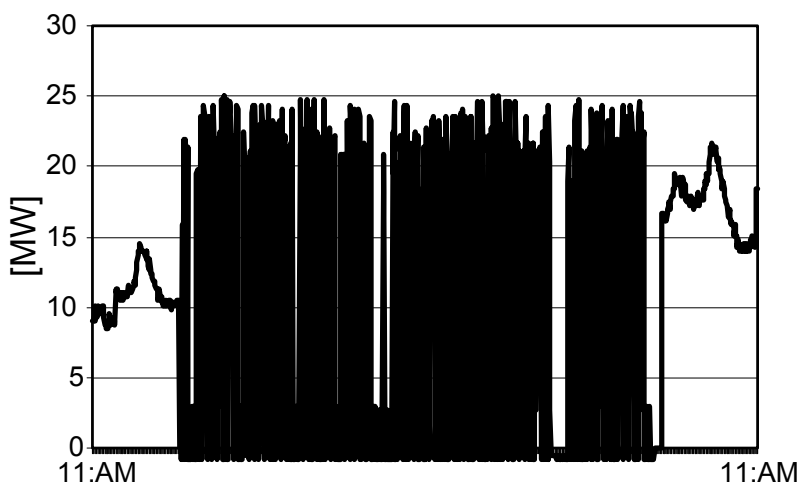

Fig. 15. Variation of the real power at PCC (HV level) 


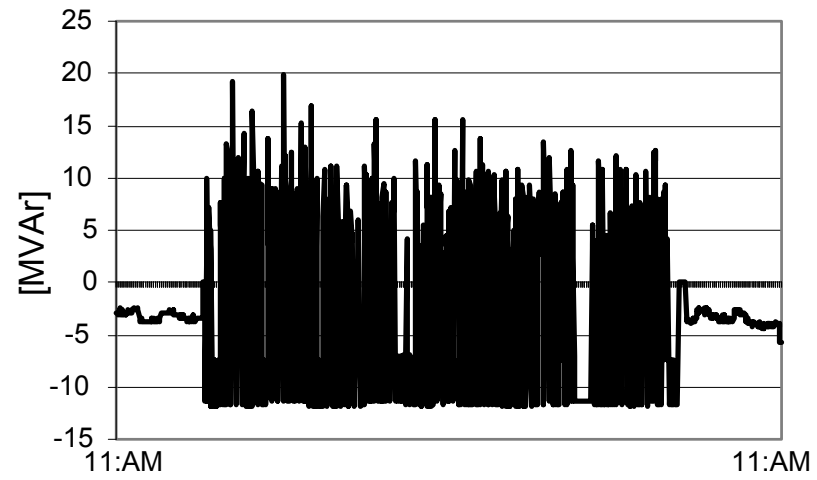

Fig. 16. Variation of the imaginary power at PCC (HV level)

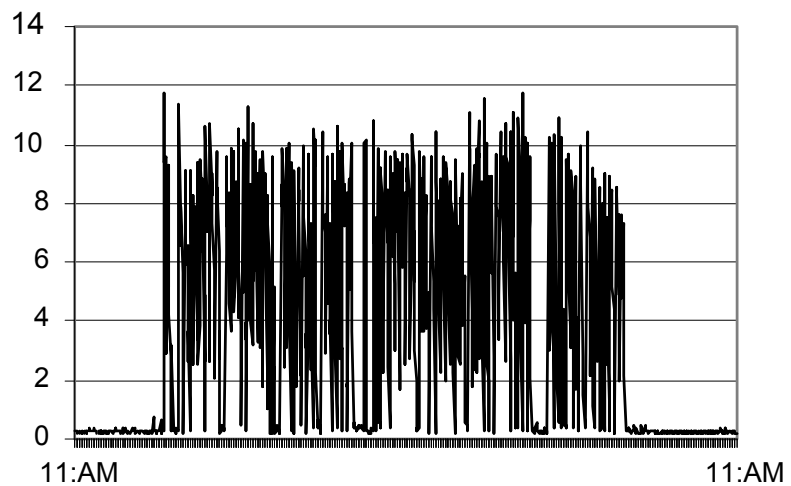

Fig. 17. Variation of $P_{s t}$ values on phase $A$.

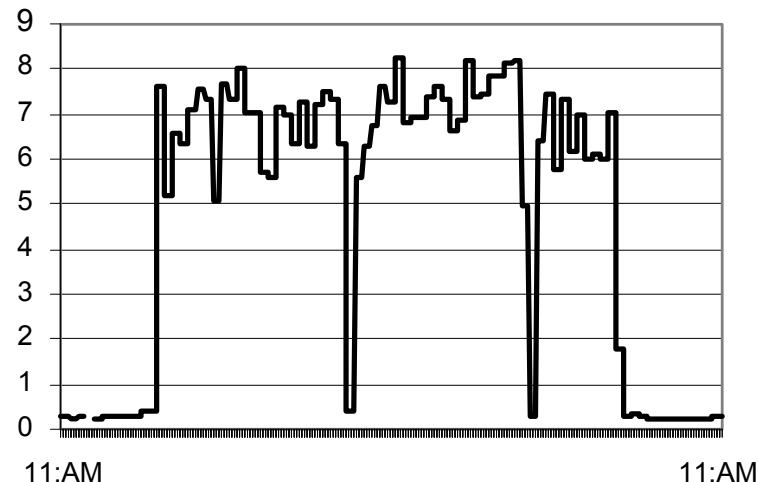

Fig. 18. Variation of $P_{l t}$ values on phase $A$. 


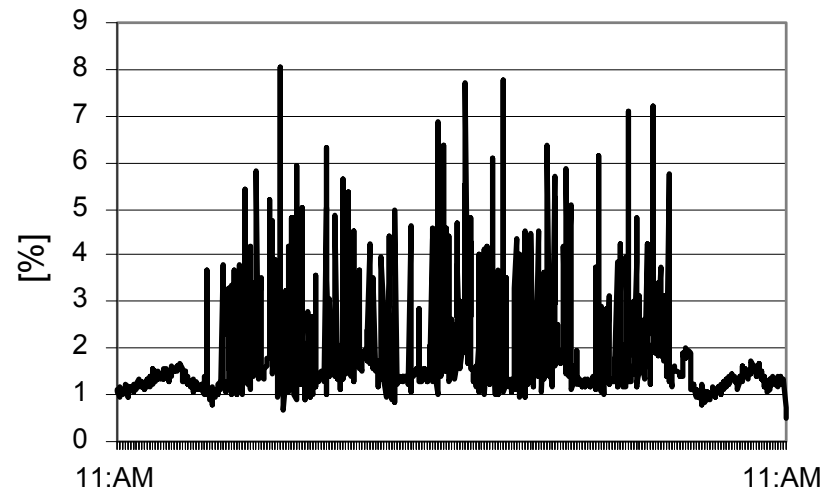

Fig. 19. Variation of $T H D V$ values on phase $A$

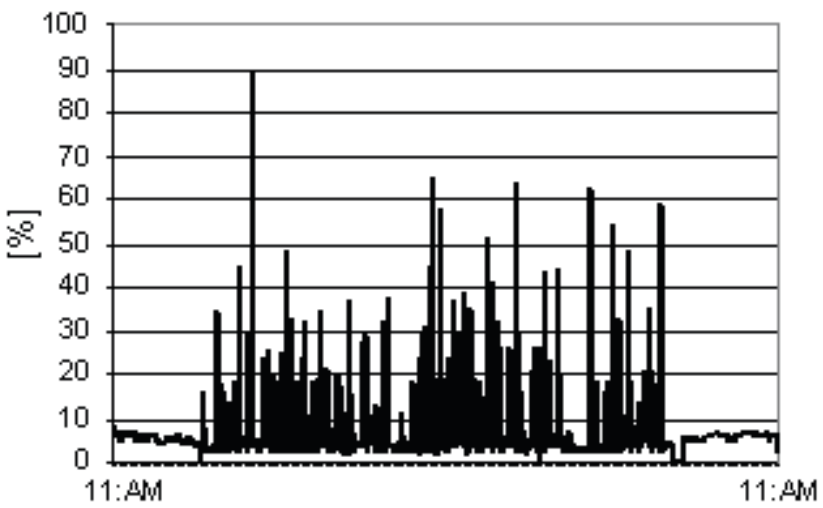

Fig. 20. Variation of THDI values on phase $A$.

Using the variation curve of the instantaneous flicker sensation the cumulative probability function $(C P F)$ can be built [4]. The cumulative probability function at the $110 \mathrm{kV}$ buses for the ac arc furnace facility is illustrated in Fig. 21.

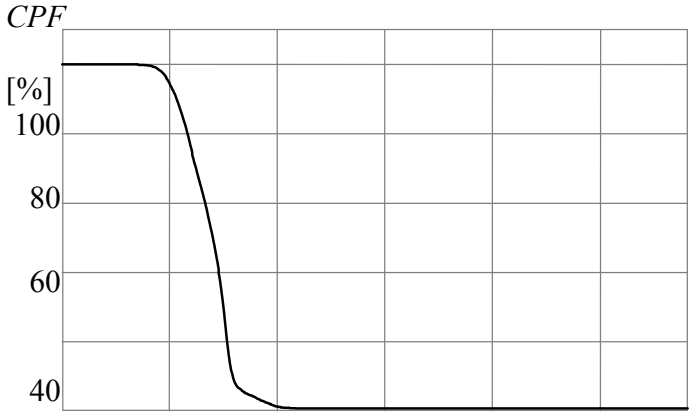

Fig. 21. Cumulative probability function CPF measured at the $110 \mathrm{kV}$ bus of the perturbing end-user 


\section{Conclusions}

The high capacity ac arc furnaces connected to the HV level can determine power quality perturbations in the transmission networks.

To quantify the amplitude of such disturbance, reference is made to the instantaneous flicker sensation $S(t)$. The value of $S(t)$ is measured by means of the so-called flickermeter. The setting-up of the flickermeter model is done in Simulink, the simulation tool, in the MATLAB environment.

For the real case studied investigated, the main power quality indices regarding harmonics and flicker levels are reported in the paper.

The aspects afore reported highlights the necessity to adopt efficient technical solutions for limiting the voltage variations until a threshold level. Thus, a precise knowledge of the perturbation characteristics and the choice of the best solution, from the technical and economical point of view, is necessary. For limiting the flicker level at PCC, the installation of a SVC will be implemented.

\section{Biographies}

Nicolae Golovanov received the Ph.D degree in Electrical Engineering from University Politehnica of Bucharest in 1975, and he is now Full Professor in the Department of Electrical Engineering, University Polytechnic of Bucharest. His areas of research include electrical end-use technologies and power quality. Dr. Golovanov is member of Energy Commission of The Romanian Academy, Chairman of Romanian Committee for Electrical End-use Technologies and member of Romanian Energy Policy Association.

George Cristian Lazaroiu received B. Sc and M. Sc. degrees from Department of Electrical Engineering, University Politehnica of Bucharest, in 2002 and respectively, 2003. He received the Ph.D. degree in Electrical Engineering, from Politecnico di Milano in 2006. His areas of research include distributed generation, power electronics and power quality.

Mariacristina Roscia, received M.S. degree (1999) and she obtained the degree PhD in Electrical Engineering at the University of Naples "Federico II". Her areas of research include Energy and Environment, Sustainable Development and renewable resources.

Dario Zaninelli, (SM'97) received the Ph.D degree in Electrical Engineering from Politecnico di Milano, in 1989, and he is now Full Professor in the Electrical Engineering Department of the Politecnico di Milano. His areas of research include power system harmonics and power system analysis. Dr. Zaninelli is a senior member of IEEE, a member of AEI and a member of the Italian National Research Council (C.N.R.) group of Electrical Power Systems.

\section{References}

[1] L. di Stasi, Electric furnaces (in Italian), Patron Editore, Bologna, Italy, 1976.

[2] E. Tironi, Electrothermal Applications (in Italian), CUSL, Milan, Italy, 2000.

[3] Electromagnetic compatibility (EMC), Part 4-30: Testing and measurement techniques Power quality measurement methods, IEC 61000-4-30/2007

[4] Flickermeter - Functional and design specifications, IEC Standard 61000-4-15, Feb. 2003

[5] Voltage characteristics of electricity supplied by public distribution systems, SR EN 50160/2007

[6] Golovanov N., Postolache P. and Toader C., Efficiency and quality of the electrical energy, Bucharest, Ed. Agir, 2007.

[7] IEEE Recommended Practice for Measurement and Limits of Voltage Fluctuations and Associated Light Flicker on AC Power Systems, IEEE Standard 1453-2004, March 2005 


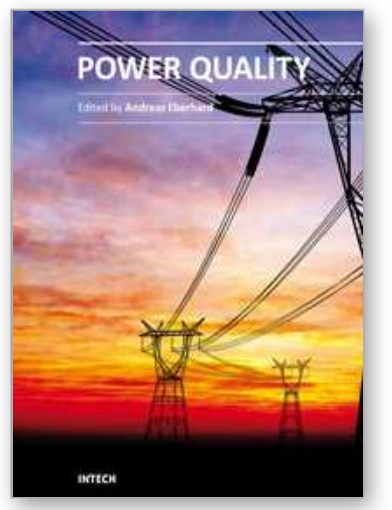

\author{
Power Quality \\ Edited by Mr Andreas Eberhard
}

ISBN 978-953-307-180-0

Hard cover, 362 pages

Publisher InTech

Published online 11, April, 2011

Published in print edition April, 2011

Almost all experts are in agreement - although we will see an improvement in metering and control of the power flow, Power Quality will suffer. This book will give an overview of how power quality might impact our lives today and tomorrow, introduce new ways to monitor power quality and inform us about interesting possibilities to mitigate power quality problems.

\title{
How to reference
}

In order to correctly reference this scholarly work, feel free to copy and paste the following:

N. Golovanov, G. C. Lazaroiu, M. Roscia and D. Zaninelli (2011). Power Quality Impact of High Capacity EndUsers, Power Quality, Mr Andreas Eberhard (Ed.), ISBN: 978-953-307-180-0, InTech, Available from: http://www.intechopen.com/books/power-quality/power-quality-impact-of-high-capacity-end-users

\section{INTECH}

open science | open minds

\section{InTech Europe}

University Campus STeP Ri

Slavka Krautzeka 83/A

51000 Rijeka, Croatia

Phone: +385 (51) 770447

Fax: +385 (51) 686166

www.intechopen.com

\section{InTech China}

Unit 405, Office Block, Hotel Equatorial Shanghai

No.65, Yan An Road (West), Shanghai, 200040, China 中国上海市延安西路65号上海国际贵都大饭店办公楼 405 单元

Phone: +86-21-62489820

Fax: $+86-21-62489821$ 
(C) 2011 The Author(s). Licensee IntechOpen. This chapter is distributed under the terms of the Creative Commons Attribution-NonCommercialShareAlike-3.0 License, which permits use, distribution and reproduction for non-commercial purposes, provided the original is properly cited and derivative works building on this content are distributed under the same license. 